\title{
Age-Specific Reference Ranges of Prostate-Specific Antigen among Saudi Men as a Representation of the Arab Population
}

\author{
Danny Munther Rabah ${ }^{a, b}$ Karim Hamda Farhat ${ }^{b} \quad$ Mohamed Abdullah Al-Atawi $^{\text {b }}$ \\ Mostafa Ahmed Arafab

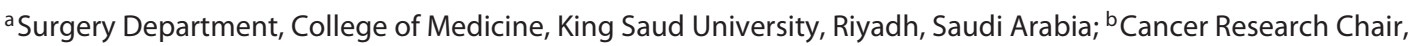 \\ College of Medicine, King Saud University, Riyadh, Saudi Arabia
}

\section{Significance of the Study}

- This is the first national study on reference levels for prostate-specific antigen (PSA) among men in the Saudi Arabian population. Our study raises the question of whether lowering the cutoff for PSA levels may improve the detection of prostate cancer in Saudi men as the disease has such a low incidence in this population.

\section{Keywords}

Prostate-specific antigen, 95th percentiles · Age-specific prostate-specific antigen serum levels · Arab countries .

Prostate cancer · Saudi Arabia

\begin{abstract}
Objective: To describe the reference ranges of serum prostate-specific antigen (PSA) in Saudi men. Materials/Subjects and Methods: Saudi males, aged 30 and above, were invited to participate in the study. Blood samples were taken from each subject to determine serum levels of PSA. Blood sugar levels, lipid profile, and anthropometric measurements were also obtained. Results: Our cohort consisted of 7,814 men; their mean PSA level was $1.24 \mathrm{ng} / \mathrm{mL}$. The majority (90.5\%) had PSA values between 0 and $2.5 \mathrm{ng} / \mathrm{mL}$. The median PSA and the 95th percentile increased steadily with age. There was a sharp increase in the 95th percentile, from $3.8 \mathrm{ng} / \mathrm{mL}$ in men between 60 and 70 years old to $6.9 \mathrm{ng} / \mathrm{mL}$ in men over 71 years old. The 95th percentiles of PSA serum levels
\end{abstract}

\begin{tabular}{ll}
\hline KARGER & $\begin{array}{l}\text { ( 2019 The Author(s) Karger } \\
\text { Published by S. Karger AG, Basel }\end{array}$ \\
E-Mail karger@karger.com & $\begin{array}{l}\text { This is an Open Access article licensed under the Creative Commons } \\
\text { Attribution-NonCommercial-4.0 International License (CC BY-NC) } \\
\text { (http://www.karger.com/Services/OpenAccessLicense), applicable to } \\
\text { the online version of the article only. Usage and distribution for com- } \\
\text { mercial purposes requires written permission. }\end{array}$
\end{tabular}

were lower in Saudi men than in the general population. Conclusions: PSA serum levels in Saudi men are lower than in other communities. Creating age-specific reference ranges could improve the sensitivity of the PSA tests by allowing the detection of treatable tumors in younger men if the threshold of $4.0 \mathrm{ng} / \mathrm{mL}$ is lowered. Furthermore, unnecessary biopsies among older men may be avoided if the threshold is increased.

(c) 2019 The Author(s)
Published by S. Karger AG, Basel

\section{Introduction}

The prostate-specific antigen (PSA) is the most widely used tumor marker for prostate cancer. An early feature of this disease is an invasion of the basal cell layer, causing a direct increase in PSA levels. PSA may increase in healthy men without being related to prostate cancer, such as in prostatic hyperplasia, where the levels increase as a result of the gradual enlargement of the prostate due to age [1]. 
Table 1. Distribution ( $n$ ) of PSA levels across age categories

\begin{tabular}{|c|c|c|c|c|c|c|}
\hline $0-2.5 \mathrm{ng} / \mathrm{mL}$ & $1,310(98.3 \%)$ & $1,610(97.5 \%)$ & $2,022(91.5 \%)$ & $1,343(85.5 \%)$ & 789 (75\%) & $7,074(90.5 \%)$ \\
\hline$>4 \mathrm{ng} / \mathrm{mL}$ & 0 & $2(0.1 \%)$ & $32(1.5 \%)$ & $75(4.8 \%)$ & $141(13.5 \%)$ & $250(3.2 \%)$ \\
\hline Total & 1,332 & 1,650 & 2,210 & 1,571 & 1,051 & 7,814 \\
\hline
\end{tabular}

Table 2. Distribution of men according to their age groups and PSA mean, median, and 95th percentiles

\begin{tabular}{lllll}
\hline \multirow{2}{*}{ Age group } & Number & \multicolumn{2}{l}{ PSA, ng/mL } \\
\cline { 3 - 5 } & & mean \pm SD & median & $\begin{array}{l}\text { 95th } \\
\text { percentile }\end{array}$ \\
\hline 30-40 years & $1,336(17.1 \%)$ & $0.87 \pm 0.5$ & 0.76 & 1.88 \\
$41-50$ years & $1,650(21.1 \%)$ & $0.93 \pm 0.58$ & 0.78 & 2.12 \\
$51-60$ years & $2,210(28.3 \%)$ & $1.17 \pm 1.07$ & 0.87 & 3.00 \\
61-70 years & $1,568(20.1 \%)$ & $1.44 \pm 1.3$ & 1.07 & 3.8 \\
$\geq 71$ years & $1,050(13.4 \%)$ & $2.05 \pm 2.2$ & 1.26 & 6.9 \\
\hline Total & 7,814 & & & \\
\hline
\end{tabular}

PSA serum levels vary in different areas of the world; Asian men have lower levels [2,3], while men of European descent and African Americans have higher levels [4,5]. The currently used cutoff of $4.0 \mathrm{ng} /$ $\mathrm{mL}$ underestimates the risk of cancer in younger men and may lead to unnecessary biopsies in older men [6]. Investigating the characteristics of serum PSA levels in various populations could be of great support for clinicians, as it would help guide prostate cancer screening practices and assess the response to therapy and tumor progression [7, 8]. The Arab world should have its own reference ranges because of the influence of environmental and genetic differences. The objective of the current study was to describe the age-specific reference ranges of PSA in Saudi men and to assess the factors that could influence the levels of this antigen in the Arab region.

\section{Materials and Methods}

\section{Subjects}

The current cross-section study was conducted at the King Saud University Medical City between December 2014 and July 2016. Riyadh, the capital of Saudi Arabia, provides free services
Table 3. Significant determinants of PSA serum levels among the Saudi population (multiple regression analysis)

\begin{tabular}{llll}
\hline Factor & $\beta$ & $t$ & Significance \\
\hline Age & 0.28 & 4.5 & 0.000 \\
BMI & 0.06 & 3.1 & 0.002 \\
Blood sugar levels & -0.03 & 2.04 & 0.04 \\
\hline
\end{tabular}

to all Saudi citizens living there and in all neighboring cities, where all Saudi citizens are covered by medical insurance. Our cohort comprised Saudi males, aged 30 years and older, who were transferred from the outpatient primary care clinics for any reason to draw blood at the laboratory services and those that came for a blood donation. They were invited to participate in the study, and objectives and rationale were explained to them. Those who agreed to participate provided signed informed consent.

Each participant filled a short questionnaire including data about their current and past health status, smoking history, prostatic diseases, and the reason for blood withdrawal. For each patient, blood sugar levels and lipid profile were retrieved from the records and anthropometric measurements obtained.

An additional $4 \mathrm{~mL}$ of blood were withdrawn from each subject for PSA analysis. The sera were isolated, spun at 2,000 $\mathrm{g}$, and stored at $-20^{\circ} \mathrm{C}$ until analyzed. Total PSA levels were measured with the total PSA kit using the Biomérieux Vidas PC Automated Immunoassay Analyzer, BioMérieux, France.

\section{Exclusion Criteria}

Any participant with past or present history of prostate cancer or any condition that might affect PSA levels, i.e., prostatitis, urinary tract infection, chronic retention, or coagulopathies, was excluded from the study. Such conditions were ascertained from records and the patients' medical history.

Any subject with high serum PSA $(>4 \mathrm{ng} / \mathrm{mL})$ was contacted for PSA retesting and confirmation of the result. Those with confirmed high PSA levels were referred to the urology clinic for reassessment, then subjected to magnetic resonance imaging and managed accordingly.

The fieldwork was conducted after approval from the ethics committee of the Faculty of Medicine, King Saud University, approval No. 10/2597/IRB. 
Table 4. Comparison of Saudi PSA 95th percentiles $(\mathrm{ng} / \mathrm{mL})$ with other populations

\begin{tabular}{lllllll}
\hline Age group & Saudi Arabia & Turkey [16] & China [10] & $\begin{array}{l}\text { White } \\
\text { Americans [11] }\end{array}$ & $\begin{array}{l}\text { African } \\
\text { Americans [12] }\end{array}$ & $\begin{array}{l}\text { Asian } \\
\text { Americans [12] }\end{array}$ \\
\hline [13]
\end{tabular}

\section{Data Analysis}

Simple descriptive statistics for serum PSA levels were computed for age by decades, including median and percentiles. Pearson correlation and regression analysis were performed to calculate the $r$ value, assess the association between age and PSA levels, and describe the most significant factors that could influence serum PSA distribution in the Saudi population. $p<0.05$ was considered significant.

\section{Results}

In all, 8,330 men were interviewed during the period of the study, 516 were excluded (102 had high PSA levels but were lost to follow-up, 20 had high PSA levels and were diagnosed with prostate cancer, 22 were over 90 years old and refused to participate in the study, $372 \mathrm{had}$ conditions that might affect their PSA levels, i.e., benign prostate hyperplasia with complications, prostatitis, urinary tract infection, and history of prostate cancer). Our final cohort included 7,814 men, ranging from 30 to 90 years old (mean of $54.69+13.17$ ). They were assigned to one of five categories, 30-40 years, 41-50 years, 51-60 years, $61-70$ years, and 71 years and above. The mean PSA level was $1.24 \mathrm{ng} / \mathrm{mL}$. PSA levels were significantly correlated with age and body mass index (BMI) $(r=0.26$ and 0.05 , and $p=0.00$ and 0.003 , respectively). The correlation with cholesterol was not significant; that with the blood sugar level was borderline significant $(p=0.05)$. Most men $(90.5 \%)$ had PSA values ranging from 0 to $2.5 \mathrm{ng} / \mathrm{mL}$; only $3.2 \%$ had PSA levels above $4 \mathrm{ng} / \mathrm{mL}$ (Table 1 ).

The mean, median, and 95th percentile of PSA levels among different age groups are depicted in Table 2 . The median increased with age until it reached $1.26 \mathrm{ng} / \mathrm{mL}$ in the older age group (over 71 years). The upper normal level (95th percentile) of PSA increased gradually with age. There was a sharp increase from $3.8 \mathrm{ng} / \mathrm{mL}$ in men aged 60-70 years to $6.9 \mathrm{ng} / \mathrm{mL}$ among men over 71 years old.
Table 3 shows the results of multiple regressions, where factors that might affect PSA levels were used to build the regression models. The stepwise method was used to eliminate nonsignificant variables. Age, BMI, and blood sugar levels, in that order, were the most significant independent factors that might influence PSA levels among our cohort.

Compared to other populations, the 95th percentiles of PSA serum levels were the lowest amongst the Saudi and Korean populations, followed by Chinese, Asian Americans, and White Americans. The highest levels were detected amongst the African American and Turkish populations (Table 4 ).

\section{Discussion}

PSA is a useful clinical tool for detecting early prostate cancer and monitoring treatment response. It is necessary to establish normal reference values for serum PSA distribution in different populations in general and in Saudi and Arab populations specifically, to improve the detection rate of prostate cancer in younger men and reduce the number of negative biopsies in older men.

The incidence of prostate cancer in Saudi Arabia is very low in comparison with the USA and some European countries, yet several cases were detected before the age of 50. In a recent study, Arafa et al. [9] argued against mass screening among the Saudi population; yet, men should start PSA blood testing and follow-up before the age of 50, through a shared decision-making process with their physicians as recently recommended by the United States Preventive S Task Force.

The current study revealed an association between serum PSA levels and age, BMI, and blood sugar levels as significant determinants in the Saudi population. The median and the 95th percentile of serum PSA levels increased steadily among the age groups. The sharp increase in the 
95th percentile from $3.8 \mathrm{ng} / \mathrm{mL}$ in the age group $60-70$ years old to $6.9 \mathrm{ng} / \mathrm{mL}$ in the age group over 71 years old might be explained by the high number of men who develop benign hyperplasia of the prostate at these ages, which in turn increases their PSA levels. This result confirms earlier reports indicating that PSA levels are age-dependent and correlate directly with age [10-15]. However, no significant correlation was found between serum PSA levels and age in a Turkish study [16], while Prcic et al. [17] reported that the correlation between percent free PSA levels and age was positive but not statistically significant, indicating a slight increase in percent free PSA levels with age.

Previous reports indicated an inverse association between PSA levels and diabetes $[18,19]$, where studies suggested an association between type 2 diabetes mellitus and a lower risk of prostate cancer. It has been hypothesized that men with long-term diabetes have a lower risk of prostate cancer than nondiabetic men [20,21]. The results of Werney et al. [22] have revealed that the predicted geometric mean PSA value was lower in the diabetic group than in the nondiabetic group $(p<0.001)$ and was lowest in men who had been diagnosed with diabetes more than 10 years previously. Diabetic men taking medication to control blood glucose levels had lower PSA levels than nondiabetic men [22]. Diabetic men have lower androgen levels than nondiabetic men, and this may partially explain their lower PSA levels [23]. In addition, diabetes might alter PSA values through impaired kidney function or as a consequence of antidiabetes medication use [24].

Regarding the correlation between PSA levels and obesity, the findings from different studies were inconsistent, probably because the values changed according to population characteristics [25]. Based on the results of $\mathrm{Oh}$ et al. [26] where patients with higher BMIs had lower PSA levels than those with lower BMIs, it can therefore be advised that the PSA threshold should be lower in obese men to distinguish between prostate cancer and benign conditions in the clinical situation.

The current study revealed lower levels of serum PSA (median, 95th percentile) among Saudi men in comparison with other populations such as Nigerian [14], Turkish [16], African American [12], and white American men [11]. The 95th percentile of Saudi men was very similar to that of Korean men [13]. Even within the same ethnic group, the PSA serum levels might differ; they are higher in Asian American men than in Chinese and Korean men. This could be attributed to food components that increase or decrease the risk of prostate cancer, including fats, vitamin A and its precursors, vitamin D metabolites, and plant estrogens [27].

PSA Age-Specific Reference Ranges among Arabs
Arab men have lower PSA levels and prostate volumes than Caucasians and slightly lower levels than Japanese men [15]. The 95th percentile and total values of Syrian men ranged from $1.7 \mathrm{ng} / \mathrm{mL}$ in the age group of $40-49$ years to $5.8 \mathrm{ng} / \mathrm{mL}$ in the group of 70-80 years [28]. Similar figures were reported for Sudan [29].

The formulation of age-specific PSA reference ranges represents an attempt to improve the sensitivity and specificity of serum PSA tests by considering age-based PSA changes. Liu et al. [30] proposed that age-specific PSA cutoffs would increase cancer detection (higher sensitivity) in younger men. Simultaneously, they could reduce the number of negative biopsies (higher specificity) in older men.

\section{Conclusion}

The present study confirms earlier reports showing that serum PSA levels are age- and ethnicity-dependent. PSA serum levels in Saudi men are lower than in other communities, and they only increased in the older age group (above 70 years). Considering the diagnosis of prostate cancer in late metastatic stages as reported from the earliest screening trial conducted in Saudi Arabia, age-specific reference ranges could improve the sensitivity of PSA tests by spotting treatable organ-confined tumors in younger men if the threshold of $4.0 \mathrm{ng} / \mathrm{mL}$ is lowered. Age-specific reference ranges could also increase the specificity of the PSA test by avoiding unnecessary biopsies if the threshold is increased for older men. Our findings raise the question of whether lowering the PSA cutoff may improve the detection of cancer in Saudi men as they have a low rate of prostate cancer. Further investigations on larger populations in different Arab countries are needed.

A limitation of this study is that it was exposed to some biases as it was a hospital-based study. Some factors that might influence PSA levels such as cycling and sexual intercourse were not revealed by the men who participated in the study. Furthermore, prostate volume, free/total PSA ratio, and PSA density were not measured.

\section{Acknowledgments}

This project was funded by the National Plan for Science, Technology, and Innovation (MAARIFAH), King Abdulaziz City for Science and Technology, Kingdom of Saudi Arabia, Award No. 12-MED2891-02. 


\section{Statement of Ethics}

The subjects were invited to participate in the study, and objectives and rationale were explained to them. Those who agreed to participate provided signed informed consent.

\section{Disclosure Statement}

The authors declare no conflict of interest

\section{References}

1 Lilja $\mathrm{H}$. Biology of prostate-specific antigen. Urology. 2003 Nov;62(5 Suppl 1):27-33.

2 Malati T, Kumari GR. Racial and ethnic variation of PSA in global population: age specific reference intervals for serum prostate specific antigen in healthy South Indian males. Indian J Clin Biochem. 2004 Jan;19(1):132-7.

3 Mehrabi S, Ghafarian Shirazi H, Rasti M, Bayat B. Analysis of serum prostate-specific antigen levels in men aged 40 years and older in Yasuj, Iran. Urol J. 2005;2(4):189-92.

$4 \mathrm{Wu}$ I, Modlin CS. Disparities in prostate cancer in African American men: what primary care physicians can do. Cleve Clin J Med. 2012 May;79(5):313-20.

5 Zhang K, Bangma $\mathrm{CH}$, Roobol MJ. Prostate cancer screening in Europe and Asia. Asian J Urol. 2017 Apr;4(2):86-95.

6 Nadler RB. The case for prostate-specific antigen screening starting at age 40. Cancer. 2008 Sep;113(6):1278-81.

7 Haythorn MR, Ablin RJ. Prostate-specific antigen testing across the spectrum of prostate cancer. Biomarkers Med. 2011 Aug;5(4):515-26.

8 Allan GM, Chetner MP, Donnelly BJ, Hagen NA, Ross D, Ruether JD, et al. Furthering the prostate cancer screening debate (prostate cancer specific mortality and associated risks). Can Urol Assoc J. 2011 Dec;5(6):416-21.

9 Arafa MA, Farhat KH, Al-Atawi MA, Rabah DM. Prostate cancer screening in a low prevalence population. Is it worth it? Saudi Med J. 2017 Jul;38(7):733-7.

10 Liu X, Wang J, Zhang SX, Lin Q. Reference ranges of age-related prostate-specific antigen in men without cancer from Beijing area. Iran J Public Health. 2013 Nov;42(11):1216-22.

11 Oesterling JE, Jacobsen SJ, Chute CG, Guess HA, Girman CJ, Panser LA, et al. Serum prostate-specific antigen in a community-based population of healthy men. Establishment of age-specific reference ranges. JAMA. 1993 Aug;270(7):860-4.
12 DeAntoni EP, Crawford ED, Oesterling JE Ross CA, Berger ER, McLeod DG, et al. Ageand race-specific reference ranges for prostate-specific antigen from a large communitybased study. Urology. 1996 Aug;48(2):234-9.

13 Choi YD, Kang DR, Nam CM, Kim YS, Cho SY, Kim SJ, et al. Age-specific prostate-specific antigen reference ranges in Korean men. Urology. 2007 Dec;70(6):1113-6.

14 Ikuerowo SO, Ajala MO, Abolarinwa AA, Omisanjo OA. Age-specific serum prostate specific antigen ranges among apparently healthy Nigerian men without clinical evidence of prostate cancer. Niger J Surg. 2016 Jan-Jun;22(1):5-8.

15 Kehinde EO, Mojiminiyi OA, Sheikh M, AlAwadi KA, Daar AS, Al-Hunayan A, et al. Age-specific reference levels of serum prostate-specific antigen and prostate volume in healthy Arab men. BJU Int. 2005 Aug;96(3): 308-12.

16 Müezzinoğlu T, Lekili M, Eser E, Uyanik BS, Büyüksu C. Population standards of prostate specific antigen values in men over 40: community based study in Turkey. Int Urol Nephrol. 2005;37(2):299-304.

17 Prcic A, Begic E, Hiros M. Actual contribution of free to total PSA ratio in prostate disease differentiation. Med Arh. 2016 Jul;70(4): 288-92.

18 Werny DM, Saraiya M, Gregg EW. Prostatespecific antigen values in diabetic and nondiabetic US men, 2001-2002. Am J Epidemiol. 2006 Nov;164(10):978-83.

19 Fukui M, Tanaka M, Kadono M, Imai S, Hasegawa G, Yoshikawa T, et al. Serum prostate-specific antigen levels in men with type 2 diabetes. Diabetes Care. 2008 May;31(5):930-1.

20 Bonovas S, Filioussi K, Tsantes A. Diabetes mellitus and risk of prostate cancer: a metaanalysis. Diabetologia. 2004 Jun;47(6):1071-8.
21 Kasper JS, Liu Y, Giovannucci E. Diabetes mellitus and risk of prostate cancer in the health professionals follow-up study. Int J Cancer. 2009 Mar 15;124(6):1398-403.

22 Werney DM, Saraiya M, Gregg EW. Prostatespecific antigen values in diabetic and nondiabetic US men, 2001-2002. Am J Epidemiol. 2006;164(10):978-83.

23 Betancourt-Albrecht M, Cunningham GR Hypogonadism and diabetes. Int J Impot Res. 2003;15 Suppl 4:S14-20.

24 Bruun L, Ekberg H, Bjørk T, Lilja H, Høglund $\mathrm{P}$, Christensson A. Rapid elimination by glomerular filtration of free prostate specific antigen and human kallikrein 2 after renal transplantation. J Urol. 2004 Apr;171(4):1432-5.

25 Hutterer G, Perrotte P, Gallina A, Walz J, Jeldres $\mathrm{C}$, Traumann $\mathrm{M}$, et al. Body mass index does not predict prostate-specific antigen or percent free prostate-specific antigen in men undergoing prostate cancer screening. Eur J Cancer. 2007 May;43(7):1180-7.

26 Oh JJ, Jeong SJ, Lee BK, Jeong CW, Byun SS, Hong SK, et al. Does obesity affect the accuracy of prostate-specific antigen (PSA) for predicting prostate cancer among men undergoing prostate biopsy. BJU Int. 2013 Aug;112(4):E265-71.

27 Capurso C, Vendemiale G. The Mediterranean diet reduces the risk and mortality of the prostate cancer: a narrative review. Front Nutr. 2017 Aug;4:38.

28 Bakir MA, Abo-Daher D. Age-specific reference ranges for prostate-specific antigen among healthy Syrian men. Int J Biol Markers. 2012 Jul;27(2):e152-9.

29 Abdrabo AA, Fadlalla AI, Fadl-Elmula IM. Age-specific reference range for serum prostate-specific antigen in Sudanese men. Saudi Med J. 2011 Sep;32(9):930-2.

30 Liu ZY, Sun YH, Xu CL, Gao X, Zhang LM, Ren SC. Age-specific PSA reference ranges in Chinese men without prostate cancer. Asian J Androl. 2009 Jan;11(1):100-3. 